\title{
Ultrasonographic Assessment of Diaphragm Function in Critically Ill Subjects
}

\author{
Michele Umbrello MD and Paolo Formenti MD
}

\author{
Introduction \\ Diaphragm Physiology \\ Ventilator-Induced Diaphragm Dysfunction \\ Assessment of Respiratory Muscle Function and Strength \\ Clinical Assessment \\ Imaging \\ Airway Pressure and Flow \\ Esophageal and Transdiaphragmatic Pressures \\ Electrical Activity of the Diaphragm \\ Bedside Ultrasonography in Critically Ill Patients \\ Measurement of Diaphragm Thickness \\ B-Mode \\ M-Mode \\ Diaphragm Displacement \\ Conclusions
}

The majority of patients admitted to the ICU require mechanical ventilation as a part of their process of care. However, mechanical ventilation itself or the underlying disease can lead to dysfunction of the diaphragm, a condition that may contribute to the failure of weaning from mechanical ventilation. However, extended time on the ventilator increases health-care costs and greatly increases patient morbidity and mortality. Nevertheless, symptoms and signs of muscle disease in a bedridden (or bed rest-only) ICU patient are often difficult to assess because of concomitant confounding factors. Conventional assessment of diaphragm function lacks specific, noninvasive, time-saving, and easily performed bedside tools or requires patient cooperation. Recently, the use of ultrasound has raised great interest as a simple, noninvasive method of quantification of diaphragm contractile activity. In this review, we discuss the physiology and the relevant pathophysiology of diaphragm function, and we summarize the recent findings concerning the evaluation of its (dys)function in critically ill patients, with a special focus on the role of ultrasounds. We describe how to assess diaphragm excursion and diaphragm thickening during breathing and the meaning of these measurements under spontaneous or mechanical ventilation as well as the reference values in health and disease. The spread of ultrasonographic assessment of diaphragm function may possibly result in timely identification of patients with diaphragm dysfunction and to a potential improvement in the assessment of recovery from diaphragm weakness. Key words: critical illness; diaphragm function; ultrasound; weaning; ventilator support. [Respir Care 2016;61(4):542-555. ( 2016 Daedalus Enterprises] 


\section{Ultrasonographic Assessment of Diaphragm Function}

\section{Introduction}

More than $40 \%$ of ICU patients require mechanical ventilation support as a part of their process of care. ${ }^{1}$ Moreover, it is well known that prolonged mechanical ventilation may lead to contractile dysfunction of respiratory muscles, ${ }^{2}$ in particular the diaphragm, causing a so-called ventilator-induced diaphragm dysfunction. The latter is defined as a loss of diaphragm force-generating capacity specifically related to the use of mechanical ventilation. . $^{3,4}$ The major clinical implication of ventilator-induced diaphragm dysfunction is that even when used for relatively short periods, mechanical ventilation can lead to substantial diaphragm weakness and could delay the process of weaning from the ventilator. ${ }^{5}$

Diseases that interfere with diaphragm innervations, contractile properties, or mechanical coupling to the chest wall can result in diaphragm dysfunction. ${ }^{6,7}$ Such dysfunction, in turn, can lead to dyspnea, decreased exercise performance, sleep-disordered breathing, constitutional symptoms, hypersomnia, reduced quality of life, atelectasis, and respiratory failure. Diaphragm dysfunction can be confirmed by a number of invasive and noninvasive tests. ${ }^{8}$ However, most of the studies available have been conducted on healthy volunteers or subjects breathing spontaneously, and only a few recent papers have focused attention on the function of respiratory muscles during the weaning process in mechanically ventilated subjects.

Moreover, the pathophysiology of weaning failure is complex, and it involves interaction between cardiopulmonary reserve, autonomic function, and musculoskeletal capacity. Thus, it may be hard to assess the interplay between those factors based on a single or a few predictors.

Indeed, monitoring respiratory muscle function in ICU patients is still an uncommon practice. One of the major challenges still lies in how to evaluate diaphragm function with a specific, noninvasive, time-saving, and easily performed bedside technique. Many tools are available, even if most of them require patient collaboration and are not specific for diaphragm dysfunction. Nevertheless, in recent times, the use of ultrasonographic evaluation of the diaphragm has raised great interest. The aim of this review is to describe the physiology and the relevant pathophysiology of diaphragm function and to summarize the recent

The authors are affiliated with Unità Operativa di Anestesia e Rianimazione, Azienda Ospedaliera San Paolo-Polo Universitario, Milano, Italy.

The authors have disclosed no conflicts of interest.

Correspondence: Michele Umbrello MD, UO Anestesia e Rianimazione, A.O. San Paolo, Polo Universitario, Via A Di Rudinì 8, 20142 Milano, Italy. E-mail: michele.umbrello@ao-sanpaolo.it.

DOI: $10.4187 /$ respcare.04412 literature concerning the evaluation of its (dys)function in critically ill patients.

\section{Diaphragm Physiology}

The rib cage, diaphragm, abdominal wall, and lungs are characterized by nonlinear stress-strain characteristics that depend on muscle activity. ${ }^{9}$ The positions, volumes, forces, and pressures for each set of initial conditions are determined by mechanical equilibrium. The geometrical complexity of the chest wall and its associated muscles of respiration make rigorous analysis of the mechanics of the respiratory system difficult. In fact, the diaphragm is a dome-shaped upward-curved structure of muscle and fibrous tissue that separates the thoracic cavity from the abdomen. The superior surface of the dome forms the bottom of the thoracic cavity, and the inferior surface forms the top of the abdominal cavity. ${ }^{10}$ As a dome, the diaphragm has peripheral attachments to structures that make up the abdominal and chest walls. Its peripheral part consists of muscular fibers that take origin from the circumference of the inferior thoracic opening and converge to insert into a central tendon. Since thoracic pressure decreases upon inspiration and draws the caval blood upward toward the right atrium, each contraction allows more blood to return to the heart, maximizing the efficacy of lowered thoracic pressure to venous return. ${ }^{11}$ The diaphragm is primarily innervated by the phrenic nerve; whereas the central portion sends sensory afferents via the phrenic nerve, the peripheral portions send sensory afferents via the intercostal (T5-T11) and subcostal nerves (T12). ${ }^{12}$ The area of contact between the diaphragm and the rib cage is referred to as the zone of apposition, and it is of great importance for proper diaphragm function (Fig. 1). The force of contraction of the zone of apposition is controlled by the abdominal muscles and significantly affects diaphragm tension. Diaphragm efficiency, in fact, largely depends upon its position and anatomical relationship with the lower rib cage.

In a seminal study, Goldman and Mead ${ }^{13}$ showed how the superior diaphragm surface is in straight relation with the entire chest wall. As consequence, the lower rib cage behaves during tidal breathing as if it is driven by transabdominal rather than trans-thoracic pressure. ${ }^{14}$ During inspiration, diaphragm muscle fibers shorten, and the diaphragm as a whole moves caudally in piston-like fashion; the dome of the diaphragm normally changes size or shape very little during tidal breathing, and the changes in muscle length are accommodated mainly by increasing and decreasing the area of apposition. ${ }^{12}$ As the diaphragm contracts, it lowers pleural pressure and increases abdominal pressure. The reduction in pleural pressure produces an inflationary effect on the lungs, but, if no other force were active, its effect on the rib cage would be deflationary. The 


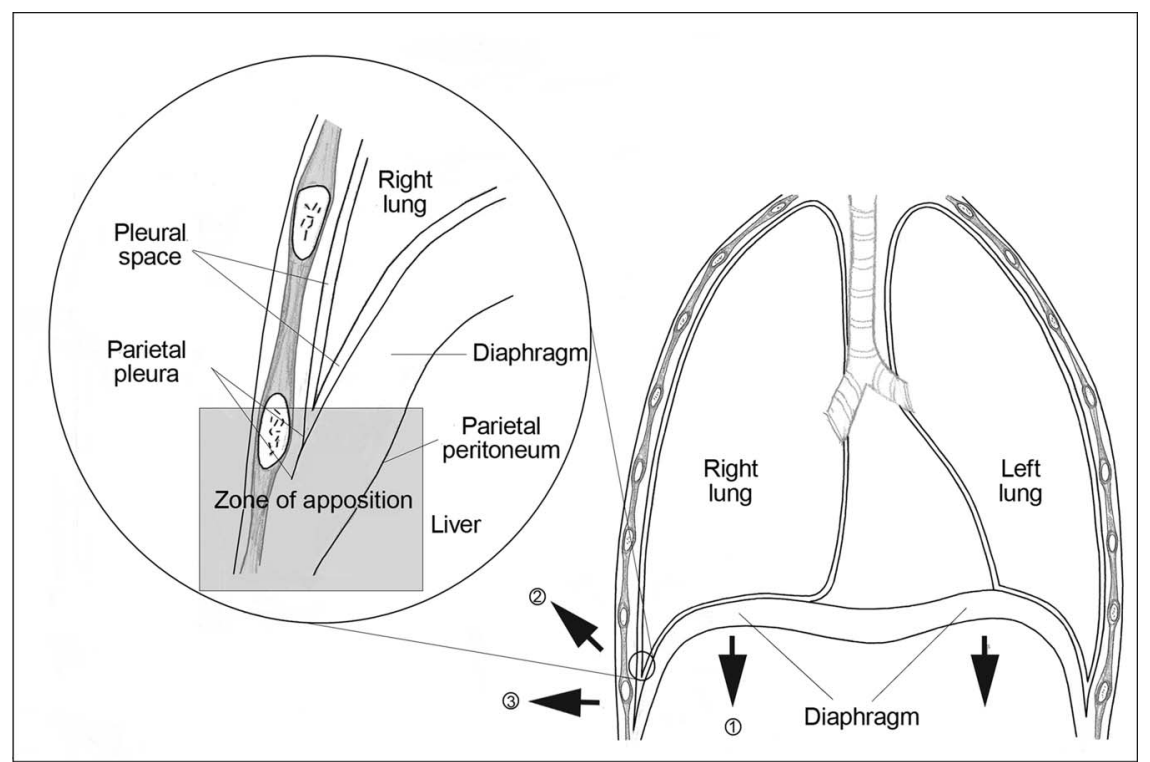

Fig. 1. Schematic view of the zone of apposition. On the right is depicted the relationship between the rib cage, right lung, and upper abdominal content in the zone of apposition. On the left, anatomical structures are magnified so that the anatomic relationship between the parietal pleura, the diaphragm, and the parietal peritoneum is highlighted. Arrows represent the forces acting on the different anatomic regions of the area. During inspiration, the diaphragm fibers shorten and the diaphragm as a whole moves caudally (1). As the diaphragm contracts, it lowers the pleural pressure and increases the abdominal pressure. The reduction in pleural pressure produces an inflationary effect on the lungs (2). The accompanying effects of increasing abdominal pressure tend to expand the rib cage (3).

accompanying effects of increasing abdominal pressure, which tends to expand the rib cage, however, more than counteract this.

It should, however, be considered that respiratory muscles comprise not only the diaphragm, but also intercostal and accessory muscles as well as muscles of the abdomen. Since all 3 groups share inspiratory and expiratory functions and work together in intricate ways, this must be accurately taken into account during weaning phases. In fact, the intercostal muscles and the accessory muscles primarily serve an inspiratory function that can be observed in the external intercostals in the upper few intercostal spaces during quiet breathing, with the lower intercostals becoming active with increased ventilation. The abdominal respiratory muscles are regarded as expiratory muscles that augment the passive recoil of the lungs. A few studies ${ }^{13,15-17}$ have demonstrated how the accessory respiratory muscles have the primary role to stabilize the chest wall and convert diaphragm contraction into intrathoracic pressure and volume changes. For these reasons, it should always be taken into account that the evaluation of single diaphragm function could be insufficient in the evaluation of the weaning process.

During spontaneous breathing, the inspiratory pressure generated by respiratory muscles $\left(\mathrm{P}_{\mathrm{mus}}\right)$ is dissipated to compel the elastic and resistive forces, as described by the motion law, $\mathrm{P}_{\text {mus }}=\left(\mathrm{R}_{\mathrm{RS}} \times \dot{\mathrm{V}}\right)+\left(\mathrm{E}_{\mathrm{RS}} \times \mathrm{V}\right)$, where $\mathrm{R}_{\mathrm{RS}}$ is resistance of the respiratory system, $\dot{V}$ is the air flow,
$\mathrm{E}_{\mathrm{RS}}$ is respiratory system elastance, and $\mathrm{V}$ is the volume above the functional residual capacity. Instead, during controlled mechanical ventilation, $\mathrm{P}_{\text {mus }}$ is equal to 0 , and the inspiratory force is generated by the ventilator $\left(\mathrm{P}_{\text {vent }}\right)$ only, as described by the equation, $\mathrm{P}_{\mathrm{vent}}=\left(\mathrm{R}_{\mathrm{RS}} \times \dot{\mathrm{V}}\right)+$ $\left(\mathrm{E}_{\mathrm{RS}} \times \mathrm{V}\right)$.

During assisted mechanical ventilation, the inspiratory muscles and the ventilator interact to generate the required pressure, with the motion law that can be described as follows: $\mathrm{P}_{\text {appl }}=\mathrm{P}_{\text {vent }}+\mathrm{P}_{\text {mus }}=\left(\mathrm{R}_{\mathrm{RS}} \times \dot{\mathrm{V}}\right)+\left(\mathrm{E}_{\mathrm{RS}} \times \mathrm{V}\right)$, where $P_{\text {appl }}$ is the total respiratory pressure. As suggested by Younes, ${ }^{18}$ the last equation could be followed by its rearrangement to isolate $\mathrm{P}_{\text {mus }}, \mathrm{P}_{\text {mus }}=\left(\mathrm{R}_{\mathrm{RS}} \times \dot{\mathrm{V}}+\mathrm{V}\right)-$ $\mathrm{P}_{\text {vent }}$, so that the relative contribution of respiratory muscles can be determined.

\section{Ventilator-Induced Diaphragm Dysfunction}

Evidence supporting the occurrence of diaphragm dysfunction in critically ill patients is scarce, although it is common experience that most mechanically ventilated patients display profound diaphragm weakness. This may depend on the presence of confounding factors, such as the underlying disease state, different modes of mechanical ventilation, medications, and newly acquired complications, which can all impair diaphragm function. ${ }^{19}$ Nevertheless, some data exist to actually support the presence of 


\section{Ultrasonographic Assessment of Diaphragm Function}

ventilator-induced diaphragm dysfunction in subjects. ${ }^{20-22}$ The decrease in diaphragm contractility is time-dependent, and it worsens as mechanical ventilation is prolonged. The effects of critical illness on respiratory muscle function are often part of a more generalized phenomenon, known as ICU-acquired weakness. In the last decade, the understanding of the molecular and cellular mechanisms underlying respiratory muscle weakness in the critically ill has been the subject of extensive research. ${ }^{23}$ Muscle atrophy can result from decreased protein synthesis, increased protein degradation, or both ${ }^{21}$; fiber remodeling with change from slow to fast fibers may reduce the endurance of the diaphragm, because fewer slow, fatigue-resistant fibers are available. ${ }^{24}$ Moreover, oxidative stress and structural injury are implicated as potential mechanisms of ventilatorinduced diaphragm dysfunction. Jaber et $\mathrm{al}^{25}$ reported the functional consequences of critical illness on respiratory muscles, showing an approximately $30 \%$ reduction in twitch airway pressure induced by magnetic phrenic nerve stimulation in the first days of invasive mechanical ventilation.

Experimental and clinical studies that have investigated ventilator-induced diaphragm dysfunction have mainly used controlled mechanical ventilation. One study showed that the contractile response of rabbit diaphragm to tetanic stimulation was decreased by almost a half after $3 \mathrm{~d}$ of controlled mechanical ventilation. ${ }^{26}$ In clinical practice, very few patients are ventilated with controlled mechanical ventilation, whereas modes like pressure support ventilation are widely used with the aim of unloading the respiratory muscles while avoiding muscle atrophy ${ }^{2}$ after resolution of the acute phase of illness. In such a mode, a variable amount of work is generated by the patient's inspiratory muscles, whereas the remainder is provided by the ventilator. ${ }^{27}$ However, an inappropriate level of pressure support may lead to fatigue and discomfort (if it is too low) or patient-ventilator asynchrony (if it is too high), ${ }^{28}$ then possibly promoting the onset of ventilator-induced diaphragm dysfunction.

The decrease in diaphragm force-generating capacity that occurs during controlled mechanical ventilation is attenuated during assisted modes of ventilation. ${ }^{29}$ Whether the decrease in diaphragm contractility observed during controlled ventilation contributes to failure to wean from the ventilator is difficult to determine. In fact, weaning failure patients have reasons other than ventilator-induced diaphragm dysfunction for respiratory muscle weakness. However, until further data are available, it seems prudent to reduce as much as possible the use of controlled mechanical ventilation in patients with acute respiratory failure.

To summarize, diaphragm function is a major determinant of the ability to successfully wean patients from mechanical ventilation. ${ }^{30}$ Concern has been raised that mechanical ventilation may itself be harmful to the diaphragm. ${ }^{31}$ In animals, ${ }^{6,32-36}$ diaphragm inactivity associated with mechanical ventilation leads to muscle fiber atrophy in the diaphragm and a reduction in its forcegenerating capacity. ${ }^{37}$ Importantly, the impact of such changes on diaphragm contractile function and the rapidity with which diaphragm atrophy develops during mechanical ventilation in humans remain unknown.

\section{Assessment of Respiratory Muscle Function and Strength}

Global respiratory muscle weakness and severe isolated weakness of the diaphragm or bilateral diaphragm paralysis cause dyspnea ${ }^{38}$ when the patient is in the supine position, with the abdominal paradox that occurs when the strength of the diaphragm is reduced to approximately one fourth of normal. ${ }^{39}$ In mechanically ventilated patients, these signs can be masked by ventilator support. Moreover, a severe respiratory muscle weakness may itself cause respiratory failure.

\section{Clinical Assessment}

Despite the tremendous increase in the number and sophistication of diagnostic tests, the most important element in the evaluation of patients with a suspected muscle weakness remains the physical examination. Unfortunately, symptoms and signs of muscle disease in a bed rest-only ICU patient are insufficient and difficult to assess because of concomitant confounding factors, such as analgesia and sedation, that are widely present. However, respiratory muscle weakness is often advanced before clinical symptoms occur. This follows from the relatively low respiratory muscle force that is required to overcome most respiratory tasks. Symptoms are thus often referred to as negative complaints, such as weakness, minimum exercise intolerance (such as raising arms), fatigue, and muscle atrophy. In neuromuscular diseases, close attention should be paid to the involvement of both inspiratory and expiratory muscles. In lung diseases, such as cystic fibrosis and COPD, inspiratory muscle weakness is often present. ${ }^{40}$ Less obvious is the detection of respiratory muscle weakness in patients with heart failure, ${ }^{41}$ cancer, and systemic diseases. In patients with asthma, ${ }^{42,43}$ respiratory muscle weakness can contribute to the sensation of dyspnea, and the assessment of respiratory muscle function may be helpful in solving the diagnostic dilemma of the unexplained dyspnea. When patients are treated with drugs that may induce myopathy, it seems prudent to assess respiratory muscle strength before initiating treatment, and proper follow-up is advised.

The most characteristic physical sign of diaphragm dysfunction is the abdominal paradox, which is the paradoxical inward motion of the abdomen as the rib cage expands 
during inspiration. This disordered breathing pattern results from compensatory use of the accessory inspiratory muscles of the rib cage and neck. When these muscles contract and lower pleural pressure, the weakened or flaccid diaphragm moves in a cephalad direction, and the abdominal wall moves inward. This paradoxical breathing pattern rarely occurs in unilateral diaphragm paralysis. When this is present in unilateral diaphragm paralysis, it suggests generalized weakness of the respiratory muscles. ${ }^{44}$ Accessory respiratory muscle recruitment, especially the sternocleidomastoid muscle, may be apparent by palpation in patients when inspiratory load exceeds the capacity of the diaphragm. ${ }^{45}$ Contraction of the abdominal muscles during expiration and subsequent relaxation as an assistance to inspiration may give the appearance of outward motion of the anterior abdominal wall during inspiration. Thus, activation of the abdominal muscles during expiration could also be regarded as a sign of respiratory muscle dysfunction.

When respiratory muscle strength is moderately to severely reduced, discrete clinical symptoms may occur, and this may prompt assessment of muscle function to help in the diagnostic process. The cardinal symptom of respiratory muscle weakness is dyspnea. In the case of severe expiratory muscle weakness, reduced cough efficiency may become an important handicap, and patients may become ventilator-dependent. In severe respiratory muscle dysfunction, vital capacity is generally reduced as a consequence of the respiratory muscle weakness, and it may become a better predictor of morbidity than measurements of respiratory muscle strength. ${ }^{6}$

Traditionally, several tools have been available to evaluate diaphragm function. However, most of them are not easily used at the bedside in the ICU and have reduced specificity and sensibility.

\section{Imaging}

Chest radiographs may reveal elevated hemidiaphragms (sensitivity of 90\%), even if the elevation of both hemidiaphragms is common in mechanically ventilated patients and has low specificity for diagnosing diaphragm dysfunction (specificity of $44 \%$ ). ${ }^{46}$

Fluoroscopy of the diaphragm was extensively used in the past, but it is no longer considered a helpful test in diagnosing diaphragm paralysis. With unilateral diaphragm paralysis, a paradoxical movement of the paralyzed hemidiaphragm can be shown, but false negative results $(>6 \%)$ occur with active contraction of the abdominal muscles during expiration. ${ }^{47}$ This technique can still be useful in the case of unilateral diaphragm palsy, especially if it is performed during a sniff maneuver. In fact, during the sniff maneuver, the paradoxical movement of the paralyzed hemidiaphragm, cephalad with inspiration, in con- trast with the rapid caudal movement of the unaffected muscle, can be easily detected. ${ }^{48}$ Computed tomography and magnetic resonance imaging have been proposed to evaluate diaphragm function, but they are not suitable for monitoring mechanically ventilated patients. ${ }^{49,50}$

\section{Airway Pressure and Flow}

The most widely used tests of global inspiratory and expiratory muscle strength are the static maximum pressures measured at the mouth $\left(\mathrm{P}_{\mathrm{Imax}}\right.$ and $\left.\mathrm{P}_{\text {Emax }}\right) \cdot{ }^{51-53}$ Both can be measured either when the patient is connected to the ventilator or during a brief disconnection using a handheld pressure monitoring device. Indeed, such voluntary maneuvers require patient cooperation and are influenced by sedation level, anxiety, and pain. These tests have the advantage of being noninvasive and easily performed at the bedside. A high $\mathrm{P}_{\text {Imax }}$ or $\mathrm{P}_{\text {Emax }}$ can exclude clinically important inspiratory or expiratory weakness. $\mathrm{P}_{\mathrm{Imax}}$ and $\mathrm{P}_{\text {Emax }}$ are influenced by age, sex, posture, lung volume, and the type of mouthpiece. ${ }^{54}$ To obtain more reliable measurements of $\mathrm{P}_{\text {Imax }}$ in ventilated and sedated patients, a 20-s end-expiratory occlusion period can be performed, ${ }^{55}$ using a one-way valve that permits exhalation. The same breath-stacking method can be used to assess inspiratory capacity in uncooperative patients. ${ }^{56} \mathrm{P}_{\text {Imax }}$ and $\mathrm{P}_{\text {Emax }}$ can be used as a global measure for respiratory muscle function and possibly to monitor the response of respiratory muscle training. Quality control of the measurements can only be obtained from inspection of the pressure-time curves. The peak pressure should be obtained in the very beginning of the maneuver. A pressure maintained for $\geq 1$ $\mathrm{s}$ is generally reported as the $\mathrm{P}_{\mathrm{Imax}}$ or $\mathrm{P}_{\mathrm{Emax}}$ (plateau pressure). ${ }^{57}$ However, one study ${ }^{58}$ has challenged the use of the plateau pressure, concluding that the peak pressure may be easier to obtain and equally reliable when subjects are well instructed.

In absolute numbers, $\mathrm{P}_{\text {Emax }}$ is roughly double $\mathrm{P}_{\text {Imax }}$ when a rigid mouthpiece is used. It is uncommon to find $P_{\text {Emax }}$ inferior to $\mathrm{P}_{\text {Imax }}$ even if in some neurological diseases, such as cervical spinal cord injury, ${ }^{59} \mathrm{P}_{\mathrm{Emax}}$ is typically more reduced than $\mathrm{P}_{\text {Imax }}$. Different studies reported varying normal values for $\mathrm{P}_{\text {Imax }}$ and $\mathrm{P}_{\text {Emax }}$ that are lower in females and fall with advancing age with large SD values of the data, which mean that lower limits of normality are approximately $50 \%$ of predicted normal values. ${ }^{60}$ Nevertheless, impressive differences are observed between the normal values reported in the literature. ${ }^{52,53,61-66} \mathrm{In}$ all models of maximal inspiratory and expiratory pressures, the explained variance is low, reflecting large inter-individual differences even when age, sex, and anthropometric values are taken into account. Therefore, a low $\mathrm{P}_{\mathrm{Imax}}$ should always be interpreted with caution. A normal $\mathrm{P}_{\text {Imax }}$, however, generally excludes clinically relevant inspiratory mus- 


\section{Ultrasonographic Assessment of Diaphragm Function}

cle pathology. Moreover, the effect of starting lung volume should be considered when assessing inspiratory/expiratory pressures. ${ }^{54}$

\section{Esophageal and Transdiaphragmatic Pressures}

The differential measurement of gastric and esophageal $\left(\mathrm{P}_{\mathrm{es}}\right)$ pressures determines the pressure developed across the diaphragm (transdiaphragmatic pressure $\left[\mathrm{P}_{\mathrm{di}}\right]$ ) and provides quantitative information concerning the mechanical behavior of this muscle in relative isolation from intercostals, accessory muscles, and elastic recoil of the chest wall. ${ }^{67}$ Measurement of $P_{d i}$ has been suggested to be used in all patients with suspected diaphragm weakness ${ }^{47}$ increasingly performed in the evaluation of patients suspected of having compromised diaphragm function, even if most of the normal values that have been published were obtained from laboratory studies.

At variance from $\mathrm{P}_{\text {Imax }}, \mathrm{P}_{\mathrm{di}}$ is a specific measure of diaphragm muscle strength. Voluntary measurements of maximum $\mathrm{P}_{\mathrm{di}}$ can be obtained by having the patient inspire as forcefully as possible against a closed airway or by having the patient perform a sniff maneuver. ${ }^{67}$ The higher the value, the greater the contribution of the diaphragm to total inspiratory effort. However, it should be kept in mind that $\mathrm{P}_{\mathrm{di}}$ measurement varies widely among individuals, and the range of $\mathrm{P}_{\mathrm{di}}$ is nearly independent of body size. ${ }^{68}$ Moreover, the volume at which the maximal $\mathrm{P}_{\mathrm{di}}$ maneuver is initiated is very important, because the diaphragm shortens progressively as lung volume increases and is able to generate less force as it shortens. Maximum pressure generation occurs at residual volume, although it is common practice to measure maximum $\mathrm{P}_{\mathrm{di}}$ at functional residual capacity. The normal range for $\mathrm{P}_{\mathrm{di}}$ depends on size, sex, body position, and the initial volume of the respiratory system during the maneuver, but a normal $\mathrm{P}_{\mathrm{di}}$ for an adult is around $100 \mathrm{~cm} \mathrm{H}_{2} \mathrm{O} .{ }^{69}$ To estimate the energy expenditure of the diaphragm, the tension-time index and pressure-time product can be calculated using $\mathrm{P}_{\mathrm{di}}{ }^{70}$

Indeed, isolated $\mathrm{P}_{\mathrm{es}}$ measurements have also enhanced our understanding of not only the pathophysiology of acute lung injury, but also the patient-ventilator interaction and weaning failure. ${ }^{71}$ By providing a practical means of quantifying respiratory effort, $\mathrm{P}_{\mathrm{es}}$ measurements may make it feasible to individualize the level of muscle unloading during mechanical ventilation. In fact, $\mathrm{P}_{\mathrm{mus}}$, the standard reference for the measurement of the pressure developed by the respiratory muscles, is based on $\mathrm{P}_{\mathrm{es}}$ measurement. ${ }^{69}$ In particular, it is generally computed as the difference between $\mathrm{P}_{\mathrm{es}}$ and the chest wall elastic recoil curve, calculated as the instant product of volume signal times chest wall elastance.

Gastric and esophageal balloons are currently extensively used for research purposes. However, their use is still uncommon in clinical care. Some of the newer ventilators have auxiliary ports to measure esophageal pressure, which is a step forward toward implementing measurement of esophageal pressure in clinical care, yet one should keep in mind that $\mathrm{P}_{\mathrm{di}}$ is variably influenced by positive pressure of the mechanical ventilator, and ideally it should be measured during a trial of spontaneous breathing (Fig. 2).

One study 72 showed that a signal generated noninvasively from flow, volume, and airway pressure using improvised resistance and elastance values can be used for monitoring patient-ventilator interaction and for providing information to optimize ventilator settings. This application makes it possible to non-invasively identify the onset and end of inspiratory efforts with reasonable accuracy. Such a signal may be used to synchronize the ventilator with the patient or simply to provide information on patient-ventilator interaction that may be helpful in making appropriate ventilator adjustments and in evaluating the patient. Moreover, the use of improvised values of $E_{R S}$ and $R_{R S}$ can be used to non-invasively derive a $P_{\text {mus }}$ estimate from the equation of motion so that monitoring of patient respiratory effort can be extended into clinical practice. ${ }^{72}$

Another approach to provide noninvasive estimates of respiratory effort has been proposed. ${ }^{73}$ The authors showed how a noninvasive $\mathrm{P}_{\text {mus }}$ can be derived from the electrical activity of the diaphragm $\left(\mathrm{E}_{\mathrm{di}}\right)$ signal displayed with neurally adjusted ventilatory assist (NAVA) ventilation, extending from the use of bedside estimates of commonly accepted standard indexes.

\section{Electrical Activity of the Diaphragm}

NAVA is a recently developed mode of mechanical ventilation, which provides proportional pressure support based on measurements of the $\mathrm{E}_{\mathrm{di}}$, which serves as a proxy for the neuronal output of the respiratory center.

With an expressly designed nasogastric tube, the $\mathrm{E}_{\mathrm{di}}$ is captured, fed to the ventilator, and used to assist the patient's breathing in synchrony with and in proportion to his/her own efforts, regardless of patient category or size. ${ }^{74}$ Because the work of the ventilator and the diaphragm is controlled by the same signal, coupling between the diaphragm and the ventilator is synchronized simultaneously.

With NAVA, the ventilator delivers a pressure proportional to the integral of $\mathrm{E}_{\mathrm{di}}{ }^{75}$ and therefore proportional to the neural output of the patient's central respiratory command. The level of pressure delivered is determined by the patient's respiratory center neural output; the ventilator is triggered and cycled off based on the $\mathrm{E}_{\mathrm{di}}$ value, which directly reflects the activity of the neural respiratory command. The assist levels are adjusted by changing the proportionality between the $\mathrm{E}_{\mathrm{di}}$ and delivered pressure. Stepwise increases in the NAVA level cause a gradual reduction 


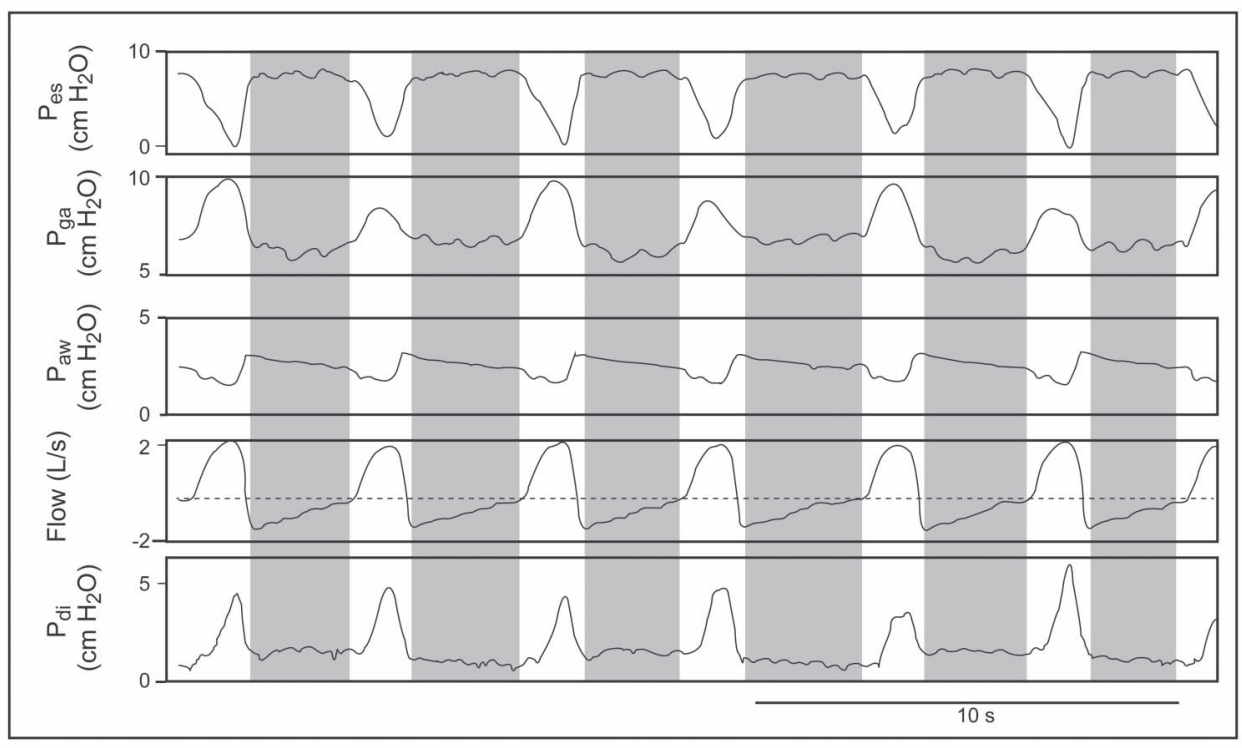

Fig. 2. Example of invasive measurement of respiratory pressures. Shown is the recording of a respiratory trace during spontaneous breathing with CPAP in a subject in whom an esophageal and a gastric balloon catheter are inserted. $\mathrm{P}_{\text {es }}=$ esophageal pressure (a proxy for pleural pressure); $P_{\text {ga }}=$ gastric pressure (a proxy for abdominal pressure); $P_{a w}=$ airway pressure; $P_{d i}=$ transdiaphragmatic pressure. White areas represent inspiration, whereas gray shaded areas depict expiration. The horizontal line represents zero flow.

in respiratory drive, and therefore the expected increase in pressure is not necessarily achieved. Due to this physiological down-regulation of the $\mathrm{E}_{\mathrm{di}}$ signal, airway pressure and tidal volume plateau at adequate levels of unloading. ${ }^{76}$ Indeed, NAVA delivers proportional assistance: the level of pressure support varies from one cycle to the next cycle and is proportional to the $\mathrm{E}_{\mathrm{di}}$ signal, which is proportional to the intensity of the diaphragm contraction. The stronger the diaphragm contraction, the greater the level of support delivered by the ventilator. If diaphragm contraction is insufficient, positive feedback will cause a more powerful $\mathrm{E}_{\mathrm{di}}$ signal and thus more support. This assistance allows proportional support to limit the periods of over- or underassistance and provides the patient with more adaptation to physiological breathing. ${ }^{77} \mathrm{~A}$ recent prospective study focusing on patient-ventilator asynchronies in NAVA and pressure support ventilation showed how NAVA reduced the risk of over- and undersupport while providing more physiological ventilation with tidal volume variability than pressure support ventilation. ${ }^{78}$ The recent commercial spread of NAVA has given the opportunity to obtain simple and minimally invasive monitoring of $\mathrm{E}_{\mathrm{di}}$, so that this index can be used to monitor patient inspiratory activity during any mode of ventilation, ${ }^{79}$ based on the tight proportionality between $\mathrm{E}_{\mathrm{di}}$ and $\mathrm{P}_{\text {mus }}{ }^{80}$ One study ${ }^{73}$ proposed the combined use of $\mathrm{P}_{\text {mus }}$ and $\mathrm{E}_{\mathrm{di}}$, previously termed neuromechanical efficiency, which is supposed to indicate the amount of pressure that respiratory muscles are generating for a unit of electrical activity. The authors found in subjects with acute respiratory failure that this index is highly variable between subjects but relatively stable in a single individual, even across different levels of assistance and ventilator modalities.

\section{Bedside Ultrasonography in Critically Ill Patients}

The relative contribution of patient effort during assisted breathing is difficult to measure in clinical conditions. Moreover, the diaphragm is inaccessible to direct clinical assessment. Bedside ultrasonography, which is already crucial in several aspects of critically illness, ${ }^{81,82}$ has recently been proposed as a simple, noninvasive method of quantification of diaphragm contractile activity. ${ }^{4}$ Ultrasound can be used to determine diaphragm excursion, ${ }^{83,84}$ which may help to identify patients with diaphragm dysfunction. ${ }^{85}$

Ultrasonographic examination can also allow for the direct visualization of diaphragm thickness in its zone of apposition. ${ }^{86}$ Thickening during active breathing has been proposed to reflect the magnitude of diaphragm effort, similar to an ejection fraction of the heart. ${ }^{87}$

A number of recent studies have employed ultrasound to measure diaphragm thickness and inspiratory thickening in ventilated subjects. Some of them focused on the feasibility and reproducibility of the technique, ${ }^{88,89}$ whereas another ${ }^{90}$ showed how with increasing levels of pressure support ventilation, parallel reductions were found between diaphragm thickening and both the diaphragm and esophageal pressure-time product, suggesting that diaphragm thickening is a reliable indicator of respiratory effort. 

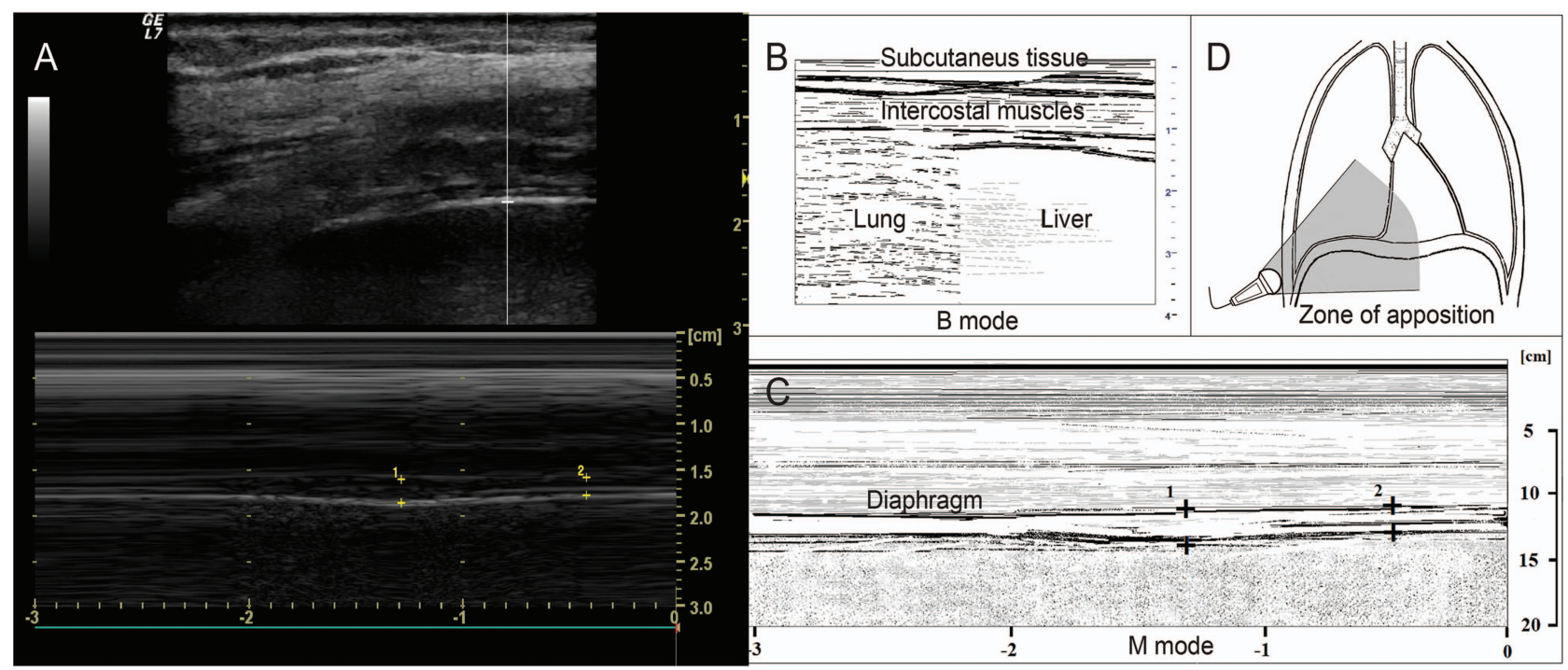

Fig. 3. Ultrasonographic assessment of diaphragm thickness. A: Ultrasonographic view of the normal diaphragm in the zone of apposition, with B-mode in the upper part and M-mode in the lower part. B: Anatomical structures that can be identified in B-mode scanning. C: Anatomical structures that can be identified in M-mode scanning. D: Probe placement to explore the diaphragm in the zone of apposition. The distance identified by plus signs 1 in $A$ and $C$ is end-inspiratory thickness, whereas the distance between plus signs 2 in the same panels is the end-expiratory thickness.

\section{Measurement of Diaphragm Thickness}

The right hemidiaphragm can be visualized in the zone of apposition of the diaphragm to the rib cage with the probe placed in the midaxillary line, between the 8th and 10th intercostal space, as a 3-layered structure consisting of pleural and peritoneal (hyperecogenic) membranes and the hypoecogenic layer of muscle itself ${ }^{86,91}$ (Fig. 3). This site is ideal for ultrasonographic visualization, since the diaphragm is bounded by soft tissue on either side and lies parallel to the skin surface and, therefore, the transducer face. The diaphragm is additionally dynamically identified as the most superficial structure that is obliterated by the leading edge of the lung upon inspiration. Eventually, it is identified by direct visualization of its contraction at the beginning of the respiratory cycle.

In order to identify the structures encountered by the ultrasound beam (from external to internal tissues), we can schematically describe: skin and soft tissues that depend on the patient's body; intercostal muscles (ie, 3 muscle bundles of $1 \mathrm{~cm}$ ) that can be considered as a unique structure having the same acoustic impendence; parietal and visceral pleurae with a thickness of $0.1 \mathrm{~mm}$; the diaphragm; and the parietal and visceral peritoneum with a thickness of $0.1 \mathrm{~mm}$.

\section{B-Mode}

Using a 7.5-10-MHz linear probe, set in B-mode and placed parallel to an intercostal space between the 8th and 10th, the inferior edge of the costophrenic angle is identified by the transient appearance of the lung artifact with breathing. Diaphragm thickness can be measured both during tidal breathing and during a maximal inspiratory effort.

One of the first studies designed to investigate how the human diaphragm changes configuration during inspiration was conducted in the early 1990s, by simultaneously measuring diaphragm thickening using ultrasound and inspired volumes with a pneumotachograph. The diaphragm thickness at functional residual capacity was reported as $2.2 \pm 0.4 \mathrm{~mm}^{3}$.

Later on, the accuracy and reproducibility of 2-dimensional ultrasound measure of diaphragm thickness in the zone of apposition with a $7.5-\mathrm{MHz}$ transducer was assessed in cadavers. The authors showed that diaphragm thickness measured by ultrasound was significantly correlated with that directly measured by a ruler. ${ }^{92}$

Since then, several studies have been performed to establish reference values of diaphragm thickness in supine healthy subjects, showing for the right hemidiaphragm mean values of $0.32 \mathrm{~cm}^{93}$ or $0.33 \mathrm{~cm},{ }^{94}$ independent of sex, age, or body constitution. More recently, Baldwin et $\mathrm{al}^{95}$ described a mean diaphragm thickness value of $1.73 \mathrm{~mm}$ (range 1.11-2.98) when measured at end expiration in healthy volunteers. In a study performed to assess the feasibility and accuracy of the method to assess diaphragm function and its contribution to respiratory work load in non-invasively ventilated subjects, the reported value was 2.19 (range $1.94-2.76$ ) $\mathrm{mm}$ at end expiration. ${ }^{88}$ 

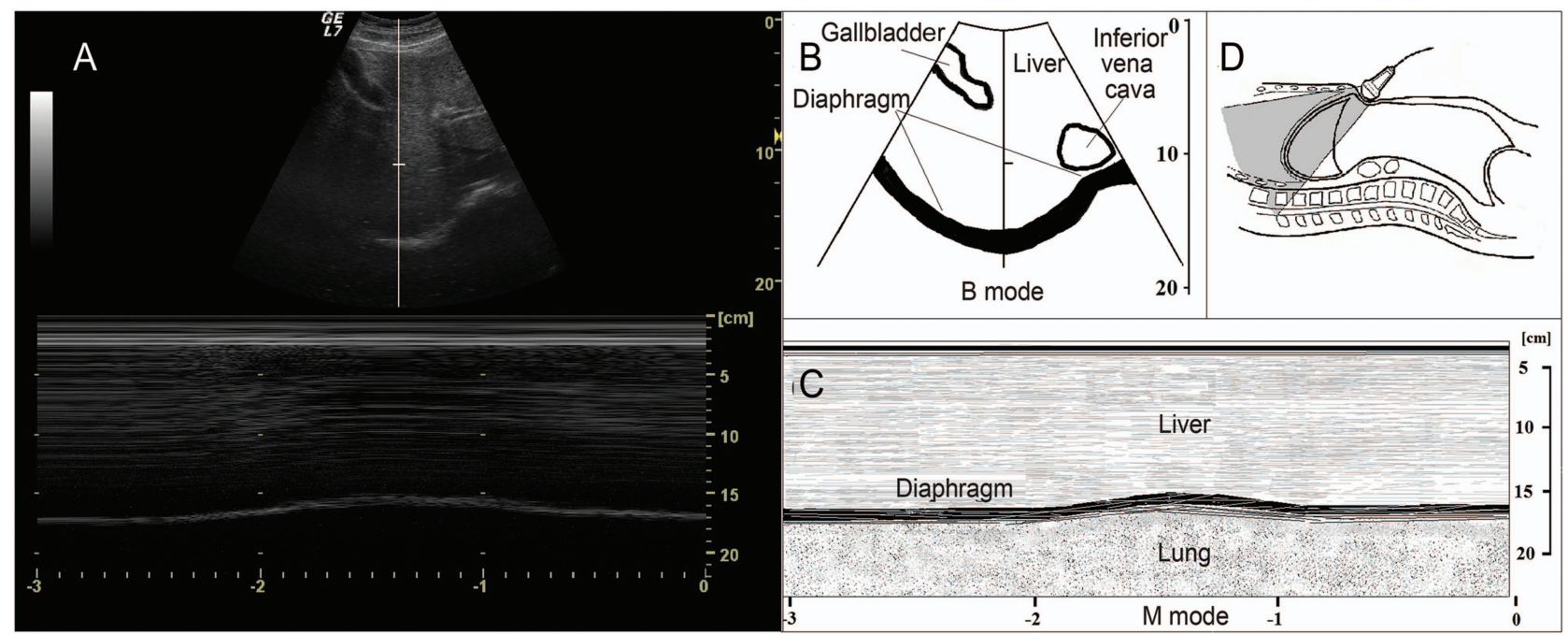

Fig. 4. Ultrasonographic assessment of diaphragm displacement. A: Ultrasonographic view of the normal diaphragm in the region of the liver dome, with B-mode in the upper part and M-mode in the lower part. B: Anatomical structures that can be identified in B-mode scanning. $\mathrm{C}$ : Anatomical structures that can be identified in M-mode scanning. D: Probe placement to explore the diaphragm in the region of the liver dome.

Thickening during active breathing has been proposed to reflect the magnitude of diaphragm effort. To better describe this phenomenon, the use of thickening fraction has been proposed, calculated as the difference between thickness at end inspiration and end expiration: thickening fraction $=$ (end-inspiratory thickness - end-expiratory thickness)/end-expiratory thickness $\times 100$.

Harper et al ${ }^{96}$ described a mean thickening fraction of $20 \%$ during tidal breathing, without significant difference between right or left hemidiaphragm in mechanically ventilated subjects. Other authors reported how left hemidiaphragm measurements could not be consistently obtained, whereas right hemidiaphragm thickness measurements are highly reproducible, particularly after marking the location of the probe. ${ }^{87}$ Some authors evaluated the variation of thickness at different lung volumes from RV to TLC in normal subjects, ${ }^{90-93}$ suggesting the use of this maximal contractile capacity of the diaphragm. Another study measured diaphragm thickness in subjects with diaphragm paralysis to monitor recovery of the muscle over time. ${ }^{97}$ Interestingly, in this latter study, no thickening was observed by ultrasound in subjects who did not recover from paralysis, thus providing useful information for both diagnosing diaphragm paralysis and indicating recovery.

Moreover, diaphragm thickness was recently studied as a weaning index. ${ }^{98}$ All subjects were ventilated in pressure support and underwent a spontaneous breathing trial while the right hemidiaphragm was visualized in the zone of apposition. The results showed how the assessment of diaphragm thickness by diaphragm ultrasound may perform similarly to other weaning indexes.
The increment of lung volume is associated with an increment in thickening fraction of about $50 \%$. Whereas inspiratory volume and muscle pressure generation are entirely collinear in spontaneously breathing patients, they are variably dissociated during mechanical ventilation. At relatively low inspiratory volumes $(<50 \%$ of inspiratory capacity), thickening of the diaphragm during inspiration arises from muscle contraction rather than from increasing thoracic volume. ${ }^{89}$ Accordingly, a given inspiratory thickening fraction value does not imply the same transdiaphragmatic pressure swing across different patients, thus limiting the utility of this measurement for precise interpatient comparison. Considering the wide variability of diaphragm thickness and thickening fraction values, these measurements are therefore best suited for qualitative comparisons of inspiratory muscle activity between patients and for quantitative comparisons of changes in inspiratory muscle activity within patients.

\section{M-Mode}

The probe is placed in the same position described previously for B-mode with the aim of identifying pleural and peritoneal membranes around the diaphragm. Diaphragm thickness is measured at end expiration and peak inspiration as the distance between the diaphragmatic pleura and the peritoneum using M-mode (Fig. 3). Goligher et al ${ }^{89}$ have suggested the measurement of end expiration and peak inspiration diaphragm thickness on 2 breaths visualized in a single $\mathrm{M}$-mode image and demonstrated the high reproducibility of this technique in mechanically ventilated subjects. 


\section{Ultrasonographic AsSESSMENT OF Diaphragm Function}

Table 1. Summary of the Most Relevant Studies Regarding Ultrasonographic Indices and Invasive Pressure Measurements to Assess Diaphragm Contractile Force and Function

\begin{tabular}{|c|c|c|c|c|}
\hline Diaphragm Index & Study & Subjects & Study Type & Results \\
\hline \multirow[t]{7}{*}{ Ultrasound displacement } & Ayoub et $\mathrm{al}^{83}$ & $\begin{array}{l}\text { Healthy, during spirometry; } \\
\text { ultrasound M-mode }\end{array}$ & Observational & $\begin{array}{l}\text { Reliable for assessing diaphragm } \\
\text { movement }\end{array}$ \\
\hline & Kentarci et al ${ }^{99}$ & Healthy, SB; M-mode both sides & Observational & $\begin{array}{l}\text { Sex, body mass index, and age may } \\
\text { affect the diaphragmatic motion }\end{array}$ \\
\hline & Toledo et al ${ }^{101}$ & SB; Ultrasound B-mode & Prospective & More accurate than chest radiograph \\
\hline & Boussuges et al ${ }^{84}$ & $\begin{array}{l}\text { Healthy subjects SB; ultrasound } \\
\text { M-mode quiet breathing, sniff, } \\
\text { and deep breathing }\end{array}$ & Observational & $\begin{array}{l}\text { Reproducible method, quantification of } \\
\text { normal values of displacement }\end{array}$ \\
\hline & Kim et $\mathrm{al}^{85}$ & $\begin{array}{l}\text { Intubated subjects who met } \\
\text { criteria for SBT; ultrasound } \\
\text { M-mode }\end{array}$ & Prospective & $\begin{array}{l}\text { Useful for diaphragm dysfunction and } \\
\text { patients at high risk of difficult } \\
\text { weaning }\end{array}$ \\
\hline & Testa et al ${ }^{100}$ & Healthy, SB & Observational & $\begin{array}{l}\text { Reliable for assessing diaphragm } \\
\text { movement }\end{array}$ \\
\hline & Matamis et $\mathrm{al}^{4}$ & $\begin{array}{l}\text { SB, ultrasound M-mode; } \\
\text { increasing resistive loading }\end{array}$ & Observational & $\begin{array}{l}\text { Useful for assessing diaphragmatic } \\
\text { motion under resistive loading }\end{array}$ \\
\hline \multirow[t]{10}{*}{$\begin{array}{l}\text { Ultrasound thickness/ } \\
\text { thickening }\end{array}$} & Ueki et $\mathrm{al}^{91}$ & Healthy, SB & Observational & $\begin{array}{l}\text { Ultrasound accurately measured } \\
\text { thickness }\end{array}$ \\
\hline & Cohn et $\mathrm{al}^{92}$ & Healthy SB and cadavers & Observational & $\begin{array}{l}\text { Ultrasound accurately measured } \\
\text { thickness. During inspiration, } \\
\text { diaphragm thickens as it shortens }\end{array}$ \\
\hline & Wait et $\mathrm{al}^{3}$ & Healthy, SB & Observational & $\begin{array}{l}\text { Ultrasound showed greater thickening } \\
\text { of the diaphragm in the zone of } \\
\text { apposition }\end{array}$ \\
\hline & Baldwin et al ${ }^{95}$ & Healthy & Observational & $\begin{array}{l}\text { Intra-rater reliability and variability of } \\
\text { a methodology using non-standard } \\
\text { recumbent positions }\end{array}$ \\
\hline & Vivier et al ${ }^{88}$ & $\begin{array}{l}\text { NIV diaphragm thickness and TF } \\
\text { at different PSV levels } \\
\text { compared with Pdi }\end{array}$ & Observational & $\begin{array}{l}\text { Ultrasound assessment of TF useful for } \\
\text { evaluating diaphragmatic function }\end{array}$ \\
\hline & Harper et al ${ }^{96}$ & Healthy, SB & Observational & $\begin{array}{l}\text { Wide variability in the degree of } \\
\text { diaphragm contractility during quiet } \\
\text { breathing. B-mode ultrasound is a } \\
\text { reliable means of determining the } \\
\text { contractility of the diaphragm }\end{array}$ \\
\hline & Boon et a ${ }^{94}$ & Healthy, SB & Observational & $\begin{array}{l}\text { Diaphragm thickness and contractility } \\
\text { are minimally affected by age, sex, } \\
\text { body habitus, or smoking history }\end{array}$ \\
\hline & Ferrari et al ${ }^{98}$ & Mechanically ventilated in PSV & Observational & $\begin{array}{l}\text { TF was significantly different between } \\
\text { patients who failed and patients who } \\
\text { succeeded SBT }\end{array}$ \\
\hline & Goligher et al ${ }^{89}$ & Mechanically ventilated & Observational & $\begin{array}{l}\text { Right hemidiaphragm thickness } \\
\text { measurements are feasible and } \\
\text { highly reproducible in ventilated } \\
\text { patients }\end{array}$ \\
\hline & Umbrello et al ${ }^{90}$ & $\begin{array}{l}\text { Mechanically ventilated under } \\
\text { assisted mechanical ventilation }\end{array}$ & Observational & $\begin{array}{l}\text { Unlike displacement, TF is a reliable } \\
\text { measurement of diaphragm } \\
\text { contractile force under assisted } \\
\text { mechanical ventilation }\end{array}$ \\
\hline \multirow[t]{2}{*}{$\begin{array}{l}\text { Transdiaphragmatic } \\
\text { pressure }\end{array}$} & Bellamare et $\mathrm{al}^{102}$ & Healthy, SB; $P_{\mathrm{di}}$ & Observational & $\begin{array}{l}\mathrm{P}_{\mathrm{di}} \text { estimates the energy expenditure of } \\
\text { the diaphragm }\end{array}$ \\
\hline & Miller et al ${ }^{67}$ & Healthy, SB; $\mathrm{P}_{\mathrm{di}}$ sniff & Observational & $\begin{array}{l}\mathrm{P}_{\mathrm{di}} \text { sniff is a reliable quantitative } \\
\text { method for assessment of diaphragm } \\
\text { strength }\end{array}$ \\
\hline
\end{tabular}


Table 1. Continued

\begin{tabular}{|c|c|c|c|c|}
\hline Diaphragm Index & Study & Subjects & Study Type & Results \\
\hline & Kimura et al ${ }^{103}$ & Intubated PSV; $\mathrm{P}_{\mathrm{di}}$ & Observational & $\begin{array}{l}P_{\mathrm{di}} \text { is helpful for titrating the required } \\
\text { PSV level }\end{array}$ \\
\hline & Polkey et al ${ }^{54}$ & Healthy, SB; $\mathrm{P}_{\mathrm{di}}$ sniff, $\mathrm{P}_{\mathrm{es}}$ & Observational & $\begin{array}{l}\mathrm{P}_{\mathrm{di}} \text { sniff and } \mathrm{P}_{\mathrm{es}} \text { are reliable for } \\
\text { assessment of diaphragmatic and } \\
\text { global inspiratory effort }\end{array}$ \\
\hline
\end{tabular}

The table represents a summary of the most important studies regarding ultrasonographic indices to assess diaphragm contractile force and function (as represented by ultrasonographic displacement and thickness or thickening) and the use of invasive pressure measurements (as represented by transdiaphragmatic pressure).

$\mathrm{SB}=$ spontaneously breathing

$\mathrm{SBT}=$ spontaneous breathing trial

NIV $=$ non-invasive ventilation

$\mathrm{TF}=$ diaphragmatic thickness

PSV $=$ pressure support ventilation

$\mathrm{P}_{\mathrm{di}}=$ transdiaphragmatic pressure

$\mathrm{P}_{\mathrm{es}}=$ esophageal pressure

\section{Diaphragm Displacement}

The cyclic caudal displacement of the diaphragm dome during inspiration/expiration can be visualized with $\mathrm{M}$ mode ultrasonography (Fig. 4). A 2-dimensional (B) mode is first used to find the best approach and to select the exploration line of each hemidiaphragm. The liver is used as a window on the right while the spleen is used for the left hemidiaphragm. A $3.5-5-\mathrm{MHz}$ convex probe is placed between the midclavicular and anterior axillary lines, in the subcostal area, and directed medially, cranially, and dorsally, so that the ultrasound beam reaches perpendicularly the posterior third of the hemidiaphragm.

With this technique, diaphragm displacement, contraction speed, inspiratory time, and total respiratory time can be measured. Kantarci et al ${ }^{99}$ described a mean left diaphragm excursion of $49 \pm 11 \mathrm{~mm}$ in healthy subjects, which was significantly lower in female, young, and underweight subjects. In a prospective study designed to determine the reference values for diaphragm amplitudes recorded by $\mathrm{M}$-mode ultrasonography, Boussuges et al ${ }^{84}$ defined the normal values during tidal and deep breathing in male and female healthy subjects $(1.8 \pm 0.3$ and $7 \pm 0.6 \mathrm{~cm}$ and $1.6 \pm 0.3$ and $5.7 \pm 1 \mathrm{~cm}$, respectively). However, all of these studies were performed in spontaneously breathing subjects, whereas the role of excursion in the functional evaluation of diaphragm contractile activity during patient-triggered mechanical ventilation is far less clear. Work from our group ${ }^{90}$ showed how this measurement was uncorrelated to any other index of inspiratory effort during patient-triggered mechanical ventilation. Indeed, diaphragm excursion during an assisted breath represents the sum of 2 forces acting in the same direction: the force of the diaphragm contraction by itself and the passive displacement of the diaphragm by the pressure provided by the ventilator, thus dismissing the role of this index as a measure of diaphragm contractile activity dur- ing assisted mechanical ventilation. Table 1 displays a summary of the most relevant studies regarding ultrasonographic indices and invasive pressure measurements for the assessment of diaphragm contractile force and function.

\section{Conclusions}

Diaphragm weakness may involve either the whole muscle or only one side. Most patients have other likely contributing causes for dyspnea, making a determination of the contribution of diaphragm dysfunction extremely difficult. Moreover, diaphragm dysfunction is common in mechanically ventilated patients and is a likely cause of weaning failure. Recent studies, on the other hand, underline the negative effect of mechanical ventilation on diaphragm structure and function (ie, ventilator-induced diaphragm dysfunction). Even if there is a scarcity of evidence directly demonstrating improved outcomes with close monitoring of the respiratory muscles, recent studies suggest that respiratory muscle monitoring can affect clinical care in the ICU. ${ }^{98}$ In general, upon physical examination, close observation of the breathing pattern reveals tachypnea and paradoxical abdominal wall retraction during inspiration. Clinical observation, sitting and supine spirometry, and measurement of maximal inspiratory and expiratory pressures may be useful but are often difficult to perform at the bedside in ICU patients. Different tools are available to assess respiratory muscle function. However, most of them are of limited value (ie, chest radiograph and fluoroscopy) or are not suitable for routine clinical care monitoring (magnetic resonance imaging, computed tomography, phrenic nerve stimulation). Circulatory biomarkers for respiratory muscle injury are indeed desirable, and they will hopefully appear in the next few years. Indeed, the accepted standard for the diagnosis of diaphragm dysfunction is the direct measurement of $\mathrm{P}_{\mathrm{di}}$. However, this testing 


\section{Ultrasonographic Assessment of Diaphragm Function}

requires specific tools, time, and expertise not always available in the general ICU. Nevertheless, ultrasonographic assessment of diaphragm function is feasible and has a relatively fast learning curve. Assessment of displacement is easily performed, even if its role in the functional assessment of diaphragm dysfunction in patients undergoing patient-triggered mechanical ventilation has recently been questioned. ${ }^{90}$ Diaphragm thickness and thickening during breathing, despite being slightly more difficult to assess, overcome the limitations of displacement and are increasingly been performed in the critical care setting. In conclusion, the increased routine use of ultrasonography in the ICU as a fast, inexpensive, and noninvasive test is expected to lead to a timely identification of patients with diaphragm dysfunction, potentially leading to a better tailoring of patient-triggered mechanical ventilation and to an improved assessment of recovery from diaphragm weakness.

\section{ACKNOWLEDGMENTS}

We are indebted to Paolo Spanu MD for valuable help with the artwork.

\section{REFERENCES}

1. Lone NI, Walsh TS. Prolonged mechanical ventilation in critically ill patients: epidemiology, outcomes and modelling the potential cost consequences of establishing a regional weaning unit. Crit Care 2011; 15(2):R102.

2. Esteban A, Anzueto A, Frutos F, Alía I, Brochard L, Stewart TE, et al. Characteristics and outcomes in adult patients receiving mechanical ventilation: a 28-day international study. JAMA 2002;287(3): 345-355.

3. Wait JL, Johnson RL. Patterns of shortening and thickening of the human diaphragm. J Appl Physiol 1997;83(4):1123-1132.

4. Matamis D, Soilemezi E, Tsagourias M, Akoumianaki E, Dimassi S, Boroli F, et al. Sonographic evaluation of the diaphragm in critically ill patients: technique and clinical applications. Intensive Care Med 2013;39(5):801-810.

5. Powers SK, Shanely RA, Coombes JS, Koesterer TJ, McKenzie M, Van Gammeren D, et al. Mechanical ventilation results in progressive contractile dysfunction in the diaphragm. J Appl Physiol 2002; 92(5):1851-1858.

6. Sassoon CS, Caiozzo VJ, Manka A, Sieck GC. Altered diaphragm contractile properties with controlled mechanical ventilation. J Appl Physiol 2002;92(6):2585-2595.

7. Shanely RA, Coombes JS, Zergeroglu AM, Webb AI, Powers SK. Short-duration mechanical ventilation enhances diaphragmatic fatigue resistance but impairs force production. Chest 2003;123(1): 195-201.

8. McCool FD, Tzelepis GE. Dysfunction of the diaphragm. N Engl J Med 2012;366(10):932-942.

9. Poole DC, Sexton WL, Farkas GA, Powers SK, Reid MB. Diaphragm structure and function in health and disease. Med Sci Sports Exerc 1997;29(6):738-754

10. Polla B, D'Antona G, Bottinelli R, Reggiani C. Respiratory muscle fibres: specialisation and plasticity. Thorax 2004;59(9):808-817.

11. Briscoe C. The interchondral joints of the human thorax. J Anat 1925;59(Pt 4):432-437.

12. Gibson GJ. Diaphragmatic paresis: pathophysiology, clinical features, and investigation. Thorax 1989;44(11):960-970.
13. Goldman MD, Mead J. Mechanical interaction between the diaphragm and rib cage. J Appl Physiol 1973;35(2):197-204.

14. Piehler JM, Pairolero PC, Gracey DR, Bernatz PE. Unexplained diaphragmatic paralysis: a harbinger of malignant disease? J Thorac Cardiovasc Surg 1982;84(6):861-864.

15. Derenne JP, Macklem PT, Roussos C. The respiratory muscles: mechanics, control, and pathophysiology. Am Rev Respir Dis 1978; 118(1):119-133.

16. Macklem PT, Gross D, Grassino GA, Roussos C. Partitioning of inspiratory pressure swings between diaphragm and intercostal/accessory muscles. J Appl Physiol 1978;44(2):200-208.

17. Danon J, Druz WS, Goldberg NB, Sharp JT. Function of the isolated paced diaphragm and the cervical accessory muscles in $\mathrm{C} 1$ quadriplegics. Am Rev Respir Dis 1979;119(6):909-919.

18. Younes M, Puddy A, Roberts D, Light RB, Quesada A, Taylor K, et al. Proportional assist ventilation: results of an initial clinical trial. Am Rev Respir Dis 1992;145(1):121-129.

19. Laghi F, Tobin MJ. Disorders of the respiratory muscles. Am J Respir Crit Care Med 2003;168(1):10-48.

20. Cattapan SE, Laghi F, Tobin MJ. Can diaphragmatic contractility be assessed by airway twitch pressure in mechanically ventilated patients? Thorax 2003;58(1):58-62.

21. Watson AC, Hughes PD, Louise Harris M, Hart N, Ware RJ, Wendon J, et al. Measurement of twitch transdiaphragmatic, esophageal, and endotracheal tube pressure with bilateral anterolateral magnetic phrenic nerve stimulation in patients in the intensive care unit. Crit Care Med 2001;29(7):1325-1331.

22. Laghi F. Assessment of respiratory output in mechanically ventilated patients. Respir Care Clin N Am 2005;11(2):173-199.

23. Levine S, Biswas C, Dierov J, Barsotti R, Shrager JB, Nguyen T, et al. Increased proteolysis, myosin depletion, and atrophic AKT-FOXO signaling in human diaphragm disuse. Am J Respir Crit Care Med 2011;183(4):483-490.

24. Hussain SN, Vassilakopoulos T. Ventilator-induced cachexia. Am J Respir Crit Care Med 2002;166(10):1307-1308.

25. Jaber S, Petrof BJ, Jung B, Chanques G, Berthet JP, Rabuel C, et al. Rapidly progressive diaphragmatic weakness and injury during mechanical ventilation in humans. Am J Respir Crit Care Med 2011; 183(3):364-371.

26. Sassoon CS, Zhu E, Caiozzo VJ. Assist-control mechanical ventilation attenuates ventilator-induced diaphragmatic dysfunction. Am J Respir Crit Care Med 2004;170(6):626-632.

27. Hess DR. Ventilator waveforms and the physiology of pressure support ventilation. Respir Care 2005;50(2):166-186; discussion 183166.

28. Thille AW, Cabello B, Galia F, Lyazidi A, Brochard L. Reduction of patient-ventilator asynchrony by reducing tidal volume during pressure-support ventilation. Intensive Care Med 2008;34(8):1477-1486.

29. Grinnan DC, Truwit JD. Clinical review: respiratory mechanics in spontaneous and assisted ventilation. Crit Care 2005;9(5):472-484.

30. Vassilakopoulos T. Ventilator-induced diaphragm dysfunction: the clinical relevance of animal models. Intensive Care Med 2008;34(1): 7-16.

31. Gayan-Ramirez G, de Paepe K, Cadot P, Decramer M. Detrimental effects of short-term mechanical ventilation on diaphragm function and IGF-I mRNA in rats. Intensive Care Med 2003;29(5):825-833.

32. Jaber S, Sebbane M, Koechlin C, Hayot M, Capdevila X, Eledjam JJ, et al. Effects of short vs. prolonged mechanical ventilation on antioxidant systems in piglet diaphragm. Intensive Care Med 2005; 31(10): 1427-1433.

33. Le Bourdelles G, Viires N, Boczkowski J, Seta N, Pavlovic D, Aubier M. Effects of mechanical ventilation on diaphragmatic contractile properties in rats. Am J Respir Crit Care Med 1994;149(6): 1539-1544. 


\section{Ultrasonographic Assessment of Diaphragm Function}

34. Picard M, Azuelos I, Jung B, Giordano C, Matecki S, Hussain S, et al. Mechanical ventilation triggers abnormal mitochondrial dynamics and morphology in the diaphragm. J Appl Physiol 2015;118(9): 1161-1171.

35. Radell PJ, Remahl S, Nichols DG, Eriksson LI. Effects of prolonged mechanical ventilation and inactivity on piglet diaphragm function. Intensive Care Med 2002;28(3):358-364.

36. Yang L, Luo J, Bourdon J, Lin MC, Gottfried SB, Petrof BJ. Controlled mechanical ventilation leads to remodeling of the rat diaphragm. Am J Respir Crit Care Med 2002;166(8):1135-1140.

37. Decramer M, Gayan-Ramirez G. Ventilator-induced diaphragmatic dysfunction: toward a better treatment? Am J Respir Crit Care Med 2004;170(11):1141-1142.

38. Davison A, Mulvey D. Idiopathic diaphragmatic weakness. BMJ 1992;304(6825):492-494.

39. Braun NM, Arora NS, Rochester DF. Respiratory muscle and pulmonary function in polymyositis and other proximal myopathies. Thorax 1983;38(8):616-623.

40. Gosselink R, Kovacs L, Ketelaer P, Carton H, Decramer M. Respiratory muscle weakness and respiratory muscle training in severely disabled multiple sclerosis patients. Arch Phys Med Rehabil 2000; 81(6):747-751.

41. Stassijns G, Lysens R, Decramer M. Peripheral and respiratory muscles in chronic heart failure. Eur Respir J 1996;9(10):2161-2167.

42. Weiner P, Magadle R, Massarwa F, Beckerman M, Berar-Yanay N. Influence of gender and inspiratory muscle training on the perception of dyspnea in patients with asthma. Chest 2002;122(1):197-201.

43. Weiner P, Magadle R, Beckerman M, Berar-Yanay N. The relationship among inspiratory muscle strength, the perception of dyspnea and inhaled $\beta 2$-agonist use in patients with asthma. Can Respir J 2002;9(5):307-312

44. Wilcox PG, Pardy RL. Diaphragmatic weakness and paralysis. Lung 1989;167(6):323-341.

45. Parthasarathy S, Jubran A, Laghi F, Tobin MJ. Sternomastoid, rib cage, and expiratory muscle activity during weaning failure. J Appl Physiol 2007;103(1):140-147.

46. Chetta A, Rehman AK, Moxham J, Carr DH, Polkey MI. Chest radiography cannot predict diaphragm function. Respir Med 2005; 99(1):39-44.

47. Davis J, Goldman M, Loh L, Casson M. Diaphragm function and alveolar hypoventilation. Q J Med 1976;45(177):87-100.

48. Tarver RD, Conces DJ Jr, Cory DA, Vix VA. Imaging the diaphragm and its disorders. J Thorac Imaging 1989;4(1):1-18.

49. Cluzel P, Similowski T, Chartrand-Lefebvre C, Zelter M, Derenne JP, Grenier PA. Diaphragm and chest wall: assessment of the inspiratory pump with MR imaging-preliminary observations. Radiology 2000;215(2):574-583.

50. Pettiaux N, Cassart M, Paiva M, Estenne M. Three-dimensional reconstruction of human diaphragm with the use of spiral computed tomography. J Appl Physiol 1997;82(3):998-1002.

51. Black LF, Hyatt RE. Maximal respiratory pressures: normal values and relationship to age and sex. Am Rev Respir Dis 1969;99(5):696702 .

52. Leech JA, Ghezzo H, Stevens D, Becklake MR. Respiratory pressures and function in young adults. Am Rev Respir Dis 1983;128(1): 17-23.

53. Bruschi C, Cerveri I, Zoia MC, Fanfulla F, Fiorentini M, Casali L, et al. Reference values of maximal respiratory mouth pressures: a population-based study. Am Rev Respir Dis 1992;146(3):790-793.

54. Polkey MI, Green M, Moxham J. Measurement of respiratory muscle strength. Thorax 1995;50(11):1131-1135.

55. Truwit JD, Marini JJ. Validation of a technique to assess maximal inspiratory pressure in poorly cooperative patients. Chest 1992; 102(4):1216-1219.
56. Marini JJ, Rodriguez RM, Lamb V. The inspiratory workload of patient-initiated mechanical ventilation. Am Rev Respir Dis 1986; 134(5):902-909.

57. American Thoracic Society/European Respiratory Society. ATS/ERS statement on respiratory muscle testing. Am J Respir Crit Care Med 2002;166(4):518-624.

58. Windisch W, Hennings E, Sorichter S, Hamm H, Criée CP. Peak or plateau maximal inspiratory mouth pressure: which is best? Eur Respir J 2004;23(5):708-713.

59. Loveridge B, Sanii R, Dubo HI. Breathing pattern adjustments during the first year following cervical spinal cord injury. Paraplegia 1992;30(7):479-488.

60. Harik-Khan RI, Wise RA, Fozard JL. Determinants of maximal inspiratory pressure: the Baltimore longitudinal study of aging. Am J Respir Crit Care Med 1998;158(5 Pt 1):1459-1464.

61. Wijkstra PJ, van der Mark TW, Boezen M, van Altena R, Postma DS, Koëter GH. Peak inspiratory mouth pressure in healthy subjects and in patients with COPD. Chest 1995;107(3):652-656.

62. Rochester DF, Arora NS. Respiratory muscle failure. Med Clin N Am 1983;67(3):573-597.

63. Vincken W, Ghezzo H, Cosio MG. Maximal static respiratory pressures in adults: normal values and their relationship to determinants of respiratory function. Bull Eur Physiopathol Respir 1987;23(5): 435-439.

64. Ringqvist $\mathrm{T}$. The ventilatory capacity in healthy subjects: an analysis of causal factors with special reference to the respiratory forces. Scand J Clin Laboratory Invest Suppl 1966;88:5-179.

65. Wilson SH, Cooke NT, Edwards RH, Spiro SG. Predicted normal values for maximal respiratory pressures in caucasian adults and children. Thorax 1984;39(7):535-538.

66. McElvaney G, Blackie S, Morrison NJ, Wilcox PG, Fairbarn MS, Pardy RL. Maximal static respiratory pressures in the normal elderly. Am Rev Respir Dis 1989;139(1):277-281.

67. Miller JM, Moxham J, Green M. The maximal sniff in the assessment of diaphragm function in man. Clin Sci 1985;69(1):91-96.

68. McCool FD, Benditt JO, Conomos P, Anderson L, Sherman CB, Hoppin FG Jr. Variability of diaphragm structure among healthy individuals. Am J Respir Crit Care Med 1997;155(4):1323-1328.

69. Benditt JO. Esophageal and gastric pressure measurements. Respir Care 2005;50(1):68-75; discussion 75-77.

70. Hess DR, MacIntyre NR, Mishoe SC, Galvin WF, Adams AB. Respiratory care: principles and practice, 2nd Edition, Sudbury, MA: Jones \& Bartlett Learning; 2012:1166.

71. Akoumianaki E, Lyazidi A, Rey N, Matamis D, Perez-Martinez N, Giraud R, et al. Mechanical ventilation-induced reverse-triggered breaths: a frequently unrecognized form of neuromechanical coupling. Chest 2013;143(4):927-938

72. Younes M, Brochard L, Grasso S, Kun J, Mancebo J, Ranieri M, et al. A method for monitoring and improving patient:ventilator interaction. Intensive Care Med 2007;33(8):1337-1346.

73. Bellani G, Mauri T, Coppadoro A, Grasselli G, Patroniti N, Spadaro $\mathrm{S}$, et al. Estimation of patient's inspiratory effort from the electrical activity of the diaphragm. Critical Care Med 2013;41(6):1483-1491.

74. Spahija J, de Marchie M, Albert M, Bellemare P, Delisle S, Beck J, Sinderby C. Patient-ventilator interaction during pressure support ventilation and neurally adjusted ventilatory assist. Crit Care Med 2010;38(2):518-526

75. Sinderby C, Navalesi P, Beck J, Skrobik Y, Comtois N, Friberg S, et al. Neural control of mechanical ventilation in respiratory failure. Nat Med 1999:5(12):1433-1436.

76. Brander L, Leong-Poi H, Beck J, Brunet F, Hutchison SJ, Slutsky AS, Sinderby C. Titration and implementation of neurally adjusted ventilatory assist in critically ill patients. Chest 2009;135(3):695703 


\section{Ultrasonographic Assessment of Diaphragm Function}

77. Schmidt M, Demoule A, Cracco C, Gharbi A, Fiamma MN, Straus $\mathrm{C}$, et al. Neurally adjusted ventilatory assist increases respiratory variability and complexity in acute respiratory failure. Anesthesiology 2010;112(3):670-681.

78. Yonis H, Crognier L, Conil JM, Serres I, Rouget A, Virtos M, et al. Patient-ventilator synchrony in neurally adjusted ventilatory assist (NAVA) and pressure support ventilation (PSV): a prospective observational study. BMC Anesthesiol 2015;15:117.

79. Colombo D, Cammarota G, Alemani M, Carenzo L, Barra FL, Vaschetto R, et al. Efficacy of ventilator waveforms observation in detecting patient-ventilator asynchrony. Crit Care Med 2011;39(11): 2452-2457.

80. Beck KC. Influence of vascular distending pressure on regional flows in isolated perfused dog lungs. J Appl Physiol 1990;69(5):18691874.

81. Beaulieu Y, Marik PE. Bedside ultrasonography in the ICU: part 2. Chest 2005;128(3):1766-1781.

82. Beaulieu Y, Marik PE. Bedside ultrasonography in the ICU: part 1. Chest 2005;128(2):881-895.

83. Ayoub J, Milane J, Targhetta R, Prioux J, Chamari K, Arbeille P, et al. Diaphragm kinetics during pneumatic belt respiratory assistance: a sonographic study in Duchenne muscular dystrophy. Neuromuscul Disord 2002;12(6):569-575.

84. Boussuges A, Gole Y, Blanc P. Diaphragmatic motion studied by M-mode ultrasonography: methods, reproducibility, and normal values. Chest 2009;135(2):391-400.

85. Kim WY, Suh HJ, Hong SB, Koh Y, Lim CM. Diaphragm dysfunction assessed by ultrasonography: influence on weaning from mechanical ventilation. Crit Care Med 2011;39(12):2627-2630.

86. Wait JL, Nahormek PA, Yost WT, Rochester DP. Diaphragmatic thickness-lung volume relationship in vivo. J Appl Physiol 1989; 67(4):1560-1568.

87. DiNino E, Gartman EJ, Sethi JM, McCool FD. Diaphragm ultrasound as a predictor of successful extubation from mechanical ventilation. Thorax 2014;69(5):423-427.

88. Vivier E, Mekontso Dessap A, Dimassi S, Vargas F, Lyazidi A, Thille AW, Brochard L. Diaphragm ultrasonography to estimate the work of breathing during non-invasive ventilation. Intensive Care Med 2012;38(5):796-803.

89. Goligher EC, Laghi F, Detsky ME, Farias P, Murray A, Brace D, et al. Measuring diaphragm thickness with ultrasound in mechanically ventilated patients: feasibility, reproducibility and validity. Intensive Care Med 2015;41(4):734.

90. Umbrello M, Formenti P, Longhi D, Galimberti A, Piva I, Pezzi A, et al. Diaphragm ultrasound as indicator of respiratory effort in critically ill patients undergoing assisted mechanical ventilation: a pilot clinical study. Crit Care 2015;19:161
91. Ueki J, De Bruin PF, Pride NB. In vivo assessment of diaphragm contraction by ultrasound in normal subjects. Thorax 1995;50(11): 1157-1161.

92. Cohn D, Benditt JO, Eveloff S, McCool FD. Diaphragm thickening during inspiration. J Appl Physiol 1997;83(1):291-296.

93. Baria MR, Shahgholi L, Sorenson EJ, Harper CJ, Lim KG, Strommen JA, et al. B-mode ultrasound assessment of diaphragm structure and function in patients with COPD. Chest 2014;146(3):680685.

94. Boon AJ, Harper CJ, Ghahfarokhi LS, Strommen JA, Watson JC, Sorenson EJ. Two-dimensional ultrasound imaging of the diaphragm: quantitative values in normal subjects. Muscle Nerve 2013; 47(6):884-889.

95. Baldwin CE, Paratz JD, Bersten AD. Diaphragm and peripheral muscle thickness on ultrasound: intra-rater reliability and variability of a methodology using non-standard recumbent positions. Respirology 2011;16(7):1136-1143.

96. Harper CJ, Shahgholi L, Cieslak K, Hellyer NJ, Strommen JA, Boon AJ. Variability in diaphragm motion during normal breathing, assessed with B-mode ultrasound. J Orthop Sports Phys Ther 2013; 43(12):927-931

97. Summerhill EM, El-Sameed YA, Glidden TJ, McCool FD. Monitoring recovery from diaphragm paralysis with ultrasound. Chest 2008;133(3):737-743

98. Ferrari G, De Filippi G, Elia F, Panero F, Volpicelli G, Aprà F. Diaphragm ultrasound as a new index of discontinuation from mechanical ventilation. Crit Ultrasound J 2014;6(1):8.

99. Kantarci F, Mihmanli I, Demirel MK, Harmanci K, Akman C, Aydogan F, et al. Normal diaphragmatic motion and the effects of body composition: determination with M-mode sonography. J Ultrasound Med 2004;23(2):255-260.

100. Testa A, Soldati G, Giannuzzi R, Berardi S, Portale G, Gentiloni Silveri N. Ultrasound M-mode assessment of diaphragmatic kinetics by anterior transverse scanning in healthy subjects. Ultrasound Med Biol 2011;37(1):44-52.

101. Toledo NS, Kodaira SK, Massarollo PC, Pereira OI, Dalmas JC, Cerri GG, et al. Left hemidiaphragmatic mobility: assessment with ultrasonographic measurement of the craniocaudal displacement of the splenic hilum and the inferior pole of the spleen. J Ultrasound Med 2006;25(1):41-49.

102. Bellemare F, Grassino A. Effect of pressure and timing of contraction on human diaphragm fatigue. J Appl Physiol Respir Environ Exerc Physiol 1982;53(5):1190-1195.

103. Kimura T, Takezawa J, Nishiwaki K, Shimada Y. Determination of the optimal pressure support level evaluated by measuring transdiaphragmatic pressure. Chest 1991;100(1):112-117. 